\title{
Analisis kesalahan dalam menyelesaikan soal cerita matematika ditinjau dari gaya belajar siswa
}

\author{
Emi Lara Safitri ${ }^{*}$, Sudi Prayitno ${ }^{2}$, Laila Hayati², Hapipi ${ }^{2}$
}

\author{
${ }^{1}$ Mahasiswa Pendidikan Matematika, FKIP, Universitas Mataram, Mataram \\ 2 Pendidikan Matematika, FKIP, Universitas Mataram, Mataram
}

emilarasafitri@gmail.com

Diterima: 17-10-2021 ; Direvisi: 26-10-2021; Dipublikasi: 30-10-2021

\begin{abstract}
This study aims to describe the errors and the causes of errors in solving mathematics word context problems on the topic of absolute value. Based on Newman's Error Analysis terms of student's lerning styles. Error analysis must continue to be carried out so that teachers know the types, causes, and solutions to overcome student errors. This type of research is descriptive qualitative. The research subjects of class X MIA 1 SMAN 1 Janapria academic year 2020/2021 were selected by purposive sampling. To deepen the research results, 2 students were selected from each type of learning style. Data collection techniques used are learning style questionnaires, tests, and interviews. Data analysis techniques used data reduction, data presentation, and conclusion. Based on the results of the data is (i) students with visual learning styles and audits mostly made errors in the stage of transformation, process skill, and encoding. While students with kinesthetic learning styles mostly made errors in the stage of comprehension, transformation, process skill, and encoding, (ii) the causes of mistakes for both students with visual, auditory, and kinesthetic learning styles are that students less understanding of the prerequisite lessons, cannot make mathematical models, and not know the steps to solve problems.
\end{abstract}

Keywords: newman's error analysis; word context problem; absolute value; learning style.

\begin{abstract}
Abstrak
Penelitian ini bertujuan untuk mendeskripsikan jenis kesalahan dan penyebab siswa melakukan kesalahan dalam menyelesaikan soal cerita matematika nilai mutlak. Analisis kesalahan dilakukan berdasarkan prosedur Newman ditinjau dari gaya belajar siswa. Analisis kesalahan harus terus dilakukan guru agar mengetahui jenis, penyebab, dan solusi untuk mengatasi kesalahan siswa. Jenis penelitian ini adalah kualitatif deskriptif. Subjek penelitian kelas X MIA 1 SMAN 1 Janapria tahun ajaran 2020/2021 dipilih dengan purposive sampling. Untuk memperdalam hasil penelitian dipilih 2 siswa dari setiap tipe gaya belajar. Teknik pengumpulan data menggunakan angket gaya belajar, tes soal cerita, dan pedoman wawancara. Teknik analisis data yaitu dengan reduksi data, penyajian data, dan penarikan kesimpulan. Dari hasil penelitian diperoleh (i) siswa dengan gaya belajar visual dan auditorial sebagian besar cenderung melakukan kesalahan pada tahap transformation, process skill, dan encoding. Sedangkan siswa bergaya belajar kinestetik sebagian besar cenderung melakukan kesalahan pada tahap comprehension, transformation, process skill, dan encoding. (ii) penyebab kesalahan baik siswa dengan gaya belajar visual, auditorial, dan kinestetik adalah siswa tidak menguasai materi prasyarat, tidak bisa membuat model matematika, dan tidak mengetahui langkah-langkah penyelesaian soal cerita.
\end{abstract}

Kata Kunci: analisis kesalahan Newman; soal cerita; nilai mutlak; gaya belajar. 


\section{PENDAHULUAN}

Persamaan dan pertidaksamaan nilai mutlak linear satu variabel merupakan materi yang memuat soal cerita yang berkaitan dengan pemecahan masalah. Dalam pembelajaran matematika, pemecahan masalah adalah inti pembelajaran yang merupakan kemampuan dasar dalam proses pembelajaran. Ada beberapa kompetensi yang harus dimiliki siswa dalam menemukan solusi dari soal cerita yang akan diselesaikan yaitu kemampuan verbal dan algoritma.

Penguasaan kemampuan verbal dan algoritma tersebut, tidak seluruhnya dimiliki oleh setiap siswa yang memiliki kemampuan yang berbeda-beda. Seperti yang terjadi pada siswa kelas X SMA Negeri 1 Janapria tahun ajaran 2020/2021. Berdasarkan hasil wawancara dengan salah satu guru matematika pada 29 Juli 2020 diketahui bahwa masih ada siswa yang mengalami kesalahan dalam menyelesaikan soal cerita. Kesalahan tersebut diantaranya, ada siswa yang sudah mengetahui permasalahan yang harus diselesaikan serta mampu melakukan operasi algoritma dengan baik, akan tetapi masih salah dalam menerjemahkan soal cerita ke dalam model matematika. Terdapat juga siswa yang sebenarnya memiliki kemampuan algoritma yang baik namun tidak mengetahui maksud dari soal sehingga siswa melakukan penghitungan dengan metode yang tidak tepat. Pada kasus lain, terdapat siswa yang kurang teliti dalam melakukan operasi algoritma yang berakibat pada kesalahan penarikan kesimpulan pada penyelesaian soal yang diberikan.

Keberagaman kesalahan yang dilakukan siswa dapat disebabkan oleh berbagai faktor salah satunya adalah proses pembelajaran di kelas. Salah satu hal yang perlu diperhatikan guru dalam melakukan pembelajaran di kelas adalah karakteristik siswa. Karakteristik siswa ini berkaitan dengan gaya belajar. Kemampuan seseorang untuk memahami dan menyerap pelajaran sudah pasti berbeda tingkatanya, ada yang cepat, sedang, dan lambat, karenanya siswa seringkali harus menempuh cara berbeda untuk bisa memahami sebuah informasi atau pelajaran yang sama. Oleh sebab itu penting bagi siswa mengenali gaya belajar yang dimiliki. Terdapat 3 macam gaya belajar berdasarkan modalitasnya yaitu visual, auditorial, dan kinestetik.

Agar dapat mengetahui secara lebih rinci mengenai kesalahan-kesalahan yang dilakukan siswa dengan gaya belajar visual, auditorial, dan kinestetik dalam menyelesaikan soal cerita matematika maka dilakukan suatu analisis kesalahan. Analisis kesalahan penting untuk dilakukan guru agar mengetahui jenis, penyebab, dan solusi untuk mengatasi kesalahan tersebut. Dalam melakukan kajian analisis kesalahan, terdapat beberapa prosedur yang dapat digunakan diantaranya dengan melakukan analisis terhadap kesalahan konseptual dan prosedural, analisis kesalahan berdasarkan langkah-langkah Polya, serta analisis kesalahan berdasarkan prosedur Newman. Jika dibandingkan dengan yang lain, analisis kesalahan berdasarkan prosedur Newman memiliki kredibilitas yang paling tinggi. 
Dalam penelitian ini, peneliti melihat jenis-jenis kesalahan menyelesaikan soal cerita yang dilakukan siswa tipe gaya belajar visual, auditorial, dan kinestetik pada materi persamaan dan pertidaksamaan nilai mutlak linear satu variabel di SMAN 1 Janapria. Soal cerita disajikan dalam tiga bentuk yaitu teks, audio, dan video. Pemilihan SMAN 1 Janapria sebagai tempat penelitian dikarenakan belum ada penelitian yang menelaah tentang kesalahan siswa dalam menyelesaikan soal cerita matematika di sekolah tersebut. Perpaduan proses analisis kesalahan Newman dan penggolongan siswa sesuai gaya belajarnya diharapkan dapat membantu guru mengetahui perbedaan jenis kesalahan, penyebab kesalahan, dan solusi apa yang dapat diberikan kepada siswa sesuai gaya belajarnya.

\section{METODE PENELITIAN}

Jenis penelitian ini adalah penelitian deskriptif kualitatif. Penelitian deskriptif kualitatif digunakan untuk mengetahui fenomena yang ada dan dalam kondisi objek yang alamiah, bukan dalam kondisi terkendali, labolatoris atau eksperimen (Sugiyono, 2015: 16). Penelitian ini dilaksanakan di SMAN 1 Janapria. Subjek penelitian kelas X MIA 1 SMAN 1 Janapria tahun ajaran 2020/2021 yang terdiri dari 25 siswa yang dipilih dengan menggunakan teknik purposive sampling. Untuk memperdalam hasil penelitian dipilih 2 siswa dari setiap tipe gaya belajar. Instrumen yang digunakan yaitu angket gaya belajar, tes soal cerita, dan pedoman wawancara. Uji validitas yang digunakan adalah validitas isi dengan bantuan 2 orang ahli dalam hal ini dosen pendidikan matematika FKIP Unram yang sebagai validator.

Teknik analisis data yang digunakan dalam penelitian ini berdasarkan pedapat Miles dan Huberman (dalam Sugiyono, 2015) yaitu reduksi data, penyajian data, dan penarikan kesimpulan. Untuk mengetahui kesalahan-kesalahan yang dilakukan siswa , terlebih dahulu siswa dibagi berdasarkan gaya belajar visual, auditorial, dan kinestetik kemudian data kesalahan yang diperoleh disesuaikan dengan indikator kesalahan Newman.

Tabel 1. Indikator Kesalahan Newman

\begin{tabular}{|c|c|c|}
\hline No & Jenis Kesalahan & Indikator Kesalahan \\
\hline 1 & $\begin{array}{l}\text { Membaca } \\
\text { (Reading) }\end{array}$ & $\begin{array}{l}\text { - Siswa tidak dapat membaca simbol dalam soal } \\
\text { - Siswa tidak dapat membaca kata kunci dalam soal }\end{array}$ \\
\hline 2 & $\begin{array}{l}\text { Memahami } \\
\text { (Comprehension) }\end{array}$ & $\begin{array}{l}\text { - Siswa tidak dapat memahami informasi yang terdapat } \\
\text { dalam soal. } \\
\text { - Siswa tidak mengetahui hal yang ditanyakan dalam soal }\end{array}$ \\
\hline 3 & $\begin{array}{l}\text { Transformasi } \\
\text { (Transformation) }\end{array}$ & $\begin{array}{l}\text { - Siswa tidak dapat membuat model matematika sesuai } \\
\text { dengan permintaan soal } \\
\text { - Siswa tidak mampu mengidentifikasi operasi/umus yang } \\
\text { sesuai untuk menyelesaikan soal }\end{array}$ \\
\hline 4 & $\begin{array}{l}\text { Keterampilan } \\
\text { Proses (Process } \\
\text { skill) }\end{array}$ & $\begin{array}{l}\text { - Siswa tidak mengetahui prosedur yang diperlukan untuk } \\
\text { melakukan operasi secara akurat. } \\
\text { - Siswa salah dalam melakukan perhitungan. }\end{array}$ \\
\hline 5 & $\begin{array}{l}\text { Penulisan Jawaban } \\
\text { (Enconding) }\end{array}$ & $\begin{array}{l}\text { - Siswa tidak dapat menulis kesimpulan jawaban sesuai } \\
\text { dengan permintaan soal. }\end{array}$ \\
\hline
\end{tabular}


Selanjutnya dicari persentase kesalahan yang dilakukan siswa untuk kemudian ditentukan kategori kesalahan yang dilakukan dengan merujuk pada kriteria kesalahan yang telah ditetapkan. Rumus yang digunakan untuk mencari persentase kesalahan siswa adalah sebagai berikut:

Keterangan:

$$
P_{j}=\frac{n_{j}}{N_{j}} \times 100 \%
$$

$P_{j}=$ Persentase kesalahan semua siswa pada jenis $j$ ( $j=1$ (reading errors), 2 (comprehension errors), 3(transformation errors), 4 (process skill errors), dan 5 (enconding errors))

$n_{j}=$ Skor kesalahan semua siswa pada jenis $j$ untuk semua soal, dan

$N_{j}=$ Skor total kemungkinan kesalahan semua siswa pada jenis $j$ untuk semua soal.

Persentase kesalahan yang dilakukan siswa dalam setiap jenis kesalahan diklasifikasikan ke dalam 5 kategori dengan mengadopsi penilaian menurut Arikunto (2016: 281) pada Tabel 2.

Tabel 2. Kategori Persentase Kesalahan

\begin{tabular}{lccl}
\hline No & \multicolumn{2}{c}{ Interval $(\%)$} & \multicolumn{1}{c}{ Kategori } \\
\hline 1 & $80 \leq P_{i j} \leq 100$ & $80 \leq P_{j} \leq 100$ & Sangat tinggi \\
2 & $60 \leq P_{i j}<80$ & $60 \leq P_{j}<80$ & Tinggi \\
3 & $40 \leq P_{i j}<60$ & $40 \leq P_{j}<60$ & Sedang \\
4 & $20 \leq P_{i j}<40$ & $20 \leq P_{j}<40$ & Rendah \\
5 & $0 \leq P_{i j}<20$ & $0 \leq P_{j}<20$ & Sangat rendah \\
\hline
\end{tabular}

\section{HASIL DAN PEMBAHASAN}

Angket gaya belajar dalam penelitian ini berisi tentang pernyataan perilaku yang sering dilakukan oleh siswa dimana setiap pernyataan tersebut mengarah pada masing-masing gaya belajar. Berdasarkan hasil angket gaya belajar diketahui bahwa siswa kelas X MIA 1 SMAN 1 Janapria tahun ajaran 2020/2021 mempunyai tipe gaya belajar yang berbedabeda. Perbandingan jumlah gaya belajar siswa kelas X MIA 1 SMAN 1 Janapria tahun ajaran 2020/2021 disajikan pada Tabel 3.

Tabel 3. Perbandingan Jumlah Gaya Belajar Siswa Kelas X MIA 1 SMAN 1 Janapria Tahun Ajaran 2020/2021

\begin{tabular}{ccc}
\hline No & Jenis Gaya Belajar & Jumlah Siswa \\
\hline 1 & Visual & 3 \\
2 & Auditorial & 14 \\
3 & Kinestetik & 3 \\
\hline
\end{tabular}


Berdasarkan Tabel 3 diketahui bahwa gaya belajar yang dominan adalah gaya belajar auditorial. Hal ini sesuai dengan keterangan yang diberikan oleh guru matematika bahwa kebiasaan-kebiasaan siswa kelas X MIA 1 yang cenderung merujuk kepada kebiasan siswa bergaya belajar auditorial seperti kebiasan siswa yang aktif dalam mengemukan pendapat, bertanya, dan berdiskusi.

Tes diagnostik digunakan untuk mengetahui jenis kesalahan yang dilakukan siswa. Tes diagnostik yang diberikan berupa soal cerita yang disajikan dalam 3 bentuk penyajian yaitu teks, audio, dan video. Secara umum kecenderungan kesalahan yang dilakukan siswa dengan gaya belajar visual, auditorial, dan kinestetik disajikan pada Tabel 4 .

Tabel 4. Kecenderungan Kesalahan Utama Tiap Gaya Belajar

\begin{tabular}{lll}
\hline No & \multicolumn{1}{c}{ Jenis Gaya Belajar } & \multicolumn{1}{c}{ Kecenderungan } \\
\hline 1 & Visual & Transformation \\
2 & Auditorial & Transformation, Process skill, \& Encoding \\
3 & Kinestetik & Comprehension \& Transformation. \\
\hline
\end{tabular}

Berdasarkan Tabel 4 terlihat bahwa kecenderungan kesalahan utama yang paling banyak dilakukan oleh siswa dengan gaya belajar auditorial. Hal ini menunjukkan bahwa siswa dengan gaya belajar auditorial memiliki pemahaman yang beragam mengenai penyelesaian soal cerita nilai mutlak yang diberikan. Untuk lebih jelasnya akan dirincikan jenis dan penyebab kesalahan yang dilakukan siswa berdasarkan gaya belajarnya sebagai berikut.

\subsection{Tingkat, Jenis, dan Penyebab Kesalahan Siswa Visual}

Subjek penelitian yang terpilih untuk tipe gaya belajar visual yaitu SV05 dan SV09. Tes diagnostik dan wawancara yang telah diselesaikan oleh kedua subjek di analisis dengan prosedur kesalahan Newman. Disajikan tingkat kesalahan yang dialami siswa dengan gaya belajar visual dalam menyelesaikan soal cerita matematika nilai mutlak ditinjau dari komponen kesalahan Newman pada Tabel 5.

Tabel 5. Tingkat Kesalahan Siswa Tipe Gaya Belajar Visual Ditinjau dari Komponen Kesalahan Newman

\begin{tabular}{clccc}
\hline No & Jenis Kesalahan & Jumlah Kesalahan & $\begin{array}{c}\text { Persentase } \\
(\%)\end{array}$ & Tingkat Kesalahan \\
\hline 1 & Reading & 7 & 25,92 & Rendah \\
2 & Comprehension & 5 & 14,81 & Sangat Rendah \\
3 & Transformation & 51 & 94,44 & Sangat Tinggi \\
4 & Process skill & 49 & 90,74 & Sangat Tinggi \\
5 & Encoding & 42 & 77,78 & Tinggi \\
\hline
\end{tabular}

Berdasarkan Tabel 5 terlihat bahwa tingkat kesalahan siswa bergaya visual dengan kategori rendah dan sangat rendah terjadi pada tahap reading dan comprehension. 
Sedikitnya kesalahan yang dilakukan terlihat dari hasil pekerjaan sebagian besar siswa visual yang menuliskan kata kunci, informasi yang diketahui, dan hal yang ditanyakan dengan lengkap terutama pada soal yang disajikan dalam bentuk teks dan audio. Hasil penelitian ini relevan dengan penelitian Hartinah, Asdar, \& Djadir (2019). Tingkat kesalahan sangat tinggi dan tinggi yaitu pada tahap transformation, process skill dan encoding. Hal ini sesuai dengan penelitian Rahmawati \& Permata (2018). Sangat tingginya kesalahan yang dilakukan terlihat dari hasil pekerjaan seluruh siswa pada hampir semua soal kurang tepat. Secara rinci hasil analisis jenis kesalahan yang dilakukan SV05 dan SV09 terhadap tes diagnostik tersaji pada Tabel 6.

Tabel 6. Kecenderungan Kesalahan Utama Siswa Bergaya Belajar Visual

\begin{tabular}{llcccccc}
\hline \multirow{2}{*}{ No } & Subjek & \multicolumn{5}{c}{ Akumulasi Kesalahan } & \multirow{2}{*}{ Kecenderungan } \\
\cline { 3 - 7 } & & R & C & T & PS & E & \\
\hline 1 & SV05 & 0 & 0 & 2 & 0 & 0 & Transformation \\
2 & SV09 & 0 & 0 & 3 & 0 & 0 & Transformation \\
\hline
\end{tabular}

Berdasarkan Tabel 6 terlihat bahwa kesalahan transformation merupakan kesalahan utama yang dilakukan oleh siswa bergaya visual. Kesalahan transformation ini berupa kesalahan dalam membuat permisalan, salah dalam membuat model matematika, dan salah dalam menuliskan sifat nilai mutlak yang digunakan untuk menyelesaikan soal. Hal ini sesuai dengan penelitian Mahmudah \& Saturni (2017) bahwa kesalahan transformasi terjadi karena siswa salah dalam mentransformasikan kata-kata dalam soal menjadi model matematika untuk diselesaikan. Berdasarkan hasil wawancara diketahui bahwa penyebab kesalahan-kesalahan yang dilakukan siswa visual yaitu karena siswa kurang memahami bagaimana membuat model matematika dari suatu soal cerita, tidak menguasai materi prasyarat, dan tidak mengetahui langkah-langkah pengerjaan soal. Adapun kesalahan process skill dan kesalahan encoding merupakan akibat dari kesalahan transformation. Hal ini sesuai dengan penelitian Nursafa'at, Sujadi, \& Riyadi (2016).

\subsection{Tingkat, Jenis, dan Penyebab Kesalahan Siswa Auditorial}

Subjek penelitian yang terpilih untuk tipe gaya belajar auditorial yaitu SA10 dan SA11. Tes diagnostik dan wawancara yang telah diselesaikan oleh kedua subjek di analisis dengan prosedur kesalahan Newman. Disajikan tingkat kesalahan yang dialami siswa dengan gaya belajar auditorial dalam menyelesaikan soal cerita matematika nilai mutlak ditinjau dari komponen kesalahan menurut prosedur Newman pada Tabel 7. 
Tabel 7. Tingkat Kesalahan Siswa Tipe Gaya Belajar Auditorial Ditinjau dari Komponen Kesalahan Newman

\begin{tabular}{clccc}
\hline No & Jenis Kesalahan & $\begin{array}{c}\text { Jumlah } \\
\text { Kesalahan }\end{array}$ & $\begin{array}{c}\text { Persentase } \\
(\%)\end{array}$ & Tingkat Kesalahan \\
\hline 1 & Reading & 26 & 20,63 & Rendah \\
2 & Comprehension & 28 & 22,22 & Rendah \\
3 & Transformation & 171 & 67,86 & Tinggi \\
4 & Process skill & 159 & 63,09 & Tinggi \\
5 & Encoding & 169 & 67,06 & Tinggi \\
\hline
\end{tabular}

Berdasarkan Tabel 7 terlihat bahwa tingkat kesalahan siswa auditorial dengan kategori rendah yaitu pada tahap reading dan comprehension. Sedikitnya kesalahan yang dilakukan terlihat dari hasil pekerjaan sebagian besar siswa auditorial yang menuliskan kata kunci, informasi yang diketahui, dan ditanyakan dengan lengkap terutama pada soal yang disajikan dalam bentuk audio. Tingkat kesalahan siswa auditorial dengan kategori tinggi terjadi pada tahap transformation, process skill, dan encoding. Tingginya kesalahan yang dilakukan siswa auditorial dikarenakan hasil pekerjaan siswa yang kurang tepat. Secara rinci hasil analisis jenis kesalahan yang dilakukan SA10 dan SA11 terhadap tes diagnostik tersaji pada Tabel 8.

Tabel 8. Kecenderungan Kesalahan Utama Siswa Bergaya Belajar Auditorial

\begin{tabular}{llllllll}
\hline No & Subjek & \multicolumn{4}{c}{ Akumulasi Kesalahan } & Kecenderungan \\
\cline { 3 - 7 } & & R & C & T & PS & E & \\
\hline 1 & SA10 & 0 & 0 & 2 & 0 & 2 & Transformation \& Encoding \\
2 & SA11 & 0 & 0 & 1 & 2 & 0 & Transformation \& Process skill. \\
\hline
\end{tabular}

Berdasarkan hasil analisis Tabel 8 terlihat bahwa kesalahan transformation, process skill, dan encoding merupakan kesalahan utama yang dilakukan oleh siswa. Kesalahan transformation yang dilakukan SA10 berupa kesalahan membuat permisalan dan kesalahan membuat model matematika. Kemudian SA11 melakukan kesalahan transformation berupa salah dalam memilih tanda pertidaksamaan yang digunakan untuk membuat model matematika dari soal cerita nilai mutlak. Penyebab kesalahan yang dilakukan kedua subjek adalah karena kurang teliti saat mengerjakan dan tidak memeriksa kembali secara keseluruhan jawabannya sebelum dikumpulkan. Hal ini sesuai dengan penelitian Agustina, Mulyono, \& Asikin (2016). Adapun kesalahan process skill yang dilakukan SA11 berupa kesalahan perhitungan. Penyebab SA11 melakukan kesalahan dikarenakan kurang teliti saat mengerjakan soal dan terburu-buru. Hal ini sesuai dengan penelitian Lestari, Hasbi, dan Lefrida (2016) dan Farida (2015). Kesalahan encoding yang dilakukan berupa kesalahan dalam menerjemahkan tanda pertidaksamaan ke dalam bentuk kata-kata dan kesalahan akibat dari kesalahan pada proses perhitungan. Penyebabnya adalah karena SA10 tidak paham bagiamana membaca tanda pertidaksamaan pada model matematika nilai mutlak dan tidak memeriksa kembali jawaban sebelum dikumpulkan. Hasil penelitian ini relevan dengan penelitian yang dilakukan oleh Haryati, Suyitno, \& Junaedi (2016) dan Utami (2016). 


\subsection{Tingkat, Jenis, dan Penyebab Kesalahan Siswa Kinestetik}

Subjek penelitian yang terpilih untuk tipe gaya belajar kinestetik yaitu SK24 dan SK25. Tes diagnostik dan wawancara yang telah diselesaikan oleh kedua subjek kemudian di analisis dengan prosedur kesalahan Newman. Disajikan tingkat kesalahan yang dialami siswa dengan gaya belajar auditorial dalam menyelesaikan soal cerita matematika nilai mutlak ditinjau dari komponen kesalahan menurut prosedur Newman pada Tabel 9.

Tabel 9. Tingkat Kesalahan Siswa Tipe Gaya Belajar Kinestetik Ditinjau dari Komponen Kesalahan Newman

\begin{tabular}{clccc}
\hline No & Jenis Kesalahan & Jumlah Kesalahan & $\begin{array}{c}\text { Persentase } \\
(\%)\end{array}$ & Tingkat Kesalahan \\
\hline 1 & Reading & 13 & 48,14 & Sedang \\
2 & Comprehension & 16 & 59,25 & Sedang \\
3 & Transformation & 51 & 94,44 & Sangat Tinggi \\
4 & Process skill & 54 & 100 & Sangat Tinggi \\
5 & Encoding & 53 & 98,14 & Sangat Tinggi \\
\hline
\end{tabular}

Berdasarkan Tabel 9 terlihat bahwa tingkat kesalahan siswa bergaya kinestetik pada jenis kesalahan reading dan comprehension tergolong sedang. Kesalahan yang dilakukan siswa kinestetik pada tahap reading dikarenakan terdapat siswa tidak menuliskan kata kunci yang terdapat dalam soal. Kesalahan pada tahap comprehension dikarenakan hasil pekerjaan sebagian besar siswa kinestetik yang tidak menuliskan informasi yang diketahui dan ditanyakan dengan lengkap. Kesalahan dengan kategori sangat tinggi terjadi pada tahap transformation, process skill, dan encoding. Sangat tingginya kesalahan yang dilakukan siswa kinestetik dikarenakan hasil pekerjaan seluruh siswa pada semua soal kurang tepat. Kesalahan-kesalahan yang dilakukan siswa kinestetik tidak terbatas pada satu bentuk penyajian soal, melainkan terjadi pada semua bentuk penyajian soal yakni teks, audio, dan video. Secara rinci hasil analisis jenis kesalahan yang dilakukan SK24 dan SK25 terhadap tes diagnostik tersaji pada Tabel 10.

Tabel 10. Kecenderungan Kesalahan Utama Siswa Bergaya Belajar Kinestetik

\begin{tabular}{llllllll}
\hline No & Subjek & \multicolumn{5}{c}{ Akumulasi Kesalahan } & \multirow{2}{*}{ Kecenderungan } \\
\cline { 3 - 7 } & & R & C & T & PS & E & \\
\hline 1 & SK24 & 0 & 0 & 6 & 0 & 0 & Transformation \\
2 & SK25 & 0 & 2 & 2 & 0 & 0 & Comprehension \& Transformation \\
\hline
\end{tabular}

Berdasarkan Tabel 10 terlihat bahwa kesalahan yang dilakukan siswa kinestetik pada tahap comprehension merupakan kesalahan utama. SK25 melakukan kesalahan utama pada soal nomor 2 dan 3. Berdasarkan hasil wawancara diketahui bahwa penyebab kesalahan dikarenakan SK25 tidak memahami maksud soal yang ditanyakan, tidak fokus dan terburu-buru saat mengerjakan soal. Hal ini sesuai dengan pendapat Deporter 
dan Hernacki (2016:118) bahwa siswa kinestetik akan kesulitan untuk fokus jika duduk diam untuk waktu yang lama. Hasil penelitian ini relevan dengan penelitian Fitriatien (2019) dan Hayati, Amrullah, \& Sripatmi (2019).

Kesalahan utama lainnya juga terlihat pada tahap transformation. Kesalahan yang dilakukan siswa kinestetik pada tahap transformation yaitu kesalahan dalam membuat permisalan, salah dalam membuat model matematika dari soal cerita, dan salah menuliskan rumus atau sifat yang sesuai untuk menyelesaikan soal. Hal ini sejalan dengan kesalahan yang ditemukan oleh Rahmawati \& Permata (2018) yaitu siswa tidak mampu mentransformasikan informasi yang mereka ketahui dalam soal kedalam kalimat matematika yang benar dan siswa salah menentukan rumus serta operasi hitung yang akan digunakan untuk menyelesaikan soal. Penyebab kesalahan dikarenakan siswa kurang memahami materi persamaan dan pertidaksamaan nilai mutlak, siswa juga tidak tahu maksud dari pertanyaan pada soal, dan siswa tidak fokus saat mengerjakan soal. Hal ini sesuai dengan penelitian Rosanggreni, Sugiarti, \& Yudianto (2018) dan Hartinah et al (2019) yang menyatakan kesalahan transformasi (transformation errors) disebabkan karena subjek belum mampu mengkoneksikan atau mengubah kalimat soal kedalam bentuk matematika dan karena ketidakpahaman subjek terhadap materi prasyarat. Adapun kesalahan process skill dan encoding merupakan akibat dari kesalahan pada tahap transformation.

Dilihat dari hasil pekerjaan siswa bergaya belajar kinestetik sering mencoba menyelesaikan soal dengan menggunakan strateginya sendiri. Walaupun strategi "cobacoba" yang siswa kinestetik gunakan seringkali tidak nyambung dan salah konsep namun siswa kinestetik tetap menuliskan secara lengkap penyelesaian dari ketiga soal. Hal ini sesuai dengan pendapat Deporter dan Hernacki (2016:118) yang menyatakan siswa bergaya belajar kinestetik mempunyai sifat ingin melakukan segala sesuatu (mencoba hal baru) serta belajar melalui kegiatan manipulasi dan praktik.

\section{PENUTUP}

Berdasarkan analisis jenis dan penyebab kesalahan dalam menyelesaikan soal cerita matematika nilai mutlak ditinjau dari gaya belajar visual, auditorial, dan kinestetik pada siswa kelas X MIA 1 SMA Negeri 1 Janapria tahun ajaran 2020/2021 dapat disimpulkan bahwa siswa dengan gaya belajar visual dan auditorial cenderung melakukan kesalahan pada tahap transformation, process skill, dan encoding. Kesalahan yang dilakukan berupa kesalahan dalam membuat model matematika dan kesalahan perhitungan. Sedangkan Siswa dengan gaya belajar kinestetik cenderung melakukan kesalahan hampir pada semua tahap yaitu comprehension, transformation, process skill, dan encoding. Kesalahan yang dilakukan siswa kinestetik berupa kesalahan tidak menuliskan informasi yang diketahui dan ditanyakan dengan lengkap dan kesalahan dalam membuat model matematika. Penyebab kesalahan dikarenakan siswa kurang memahami maksud soal, kurang menguasai materi nilai mutlak, kurang memahami cara 
membuat model matematika dari suatu soal cerita, dan lupa langkah-langkah pengerjaan yang sesuai untuk menyelesaikan soal.

\section{REKOMENDASI}

Rekomendasi penelitian selanjutnya agar terlebih dahulu siswa diberikan pembelajaran dalam bentuk teks, audio, dan video untuk kemudian dites dengan soal cerita yang disajikan dalam ketiga bentuk penyajian sesuai dengan pembelajaran yang telah diberikan. Dengan melakukan hal tersebut diharapkan hasil yang diperoleh akan lebih mendetail dan akurat.

\section{REFERENSI}

Agustina, I. R., \& , Mulyono, M. A. (2016). Analisis Kesalahan Siswa Kelas VIII dalam Menyelesaikan Soal Matematika Bentuk Uraian Berdasarkan Taksonomi Solo. Unnes Journal of Mathematics Education, 5(2), 84-91. https://doi.org/10.15294/ujme.v5i2.11399

Arikunto, S. (2016). Manajemen Penelitian. Jakarta: Rineka Cipta.

Deporter, B., \& Hernacki, M. (2016). Quantum Learning: Membiasakan Belajar Nyaman dan Menyenangkan. Bandung: Kaifa.

Farida, N. (2015). Analisis Kesalahan Siswa Smp Kelas VIII dalam Menyelesaikan Masalah Soal Cerita Matematika. Jurnal Pendidikan Matematika FKIP Univ. Muhammadiyah Metro, 4(2), 42-52. http://dx.doi.org/10.24127/ajpm.v4i2.306

Fitriatien, S. R. (2019). Analisis Kesalahan dalam Menyelesaikan Soal Cerita Matematika Berdasarkan Newman. Jurnal Ilmiah Pendidikan Matematika, 4(1), 53-64. https://doi.org/10.26877/jipmat.v4i1.3550

Hartinah, S., Asdar., \& Djadir. (2019). Deskripsi Kesalahan Siswa dalam Menyelesaikan Soal Cerita Matematika Materi Perbandingan Ditinjau Dari Gaya Belajar Siswa. Issues in Mathematics Education, 3(1), 30-38. https://doi.org/10.35580/imed

Haryati, T., Suyitno, I., \& Junaedi. (2016). Analisis Kesalahan Siswa SMP Kelas VII dalam Menyelesaikan Soal Cerita Pemecahan Masalah Berdasarkan Prosedur Newman. Unnes Journal of Mathematics Education, 5(1), 8-15. https://doi.org/10.15294/ujme.v5i1.9341

Hayati, L., Amrullah., \& Sripatmi. (2019). Analisis Kesalahan Mahasiswa dalam Menyelesaikan Soal Materi Statistika Matematika. Seminar Nasional FKIP Universitas Mataram, 249253. https://jurnalfkip.unram.ac.id/index.php/PSN/article/view/2208

Lestari, A. P., Hasbi, M., \& Lefrida, R. (2016). Analisis Kesalahan Siswa Kelas IX Dalam Menyelesaikan Soal Cerita Keliling Dan Luas Lingkaran Di SMP Al-Azhar Palu. Jurnal Elektronik Pendidikan Matematika Tadulako, 3(4), 373-385. http://jurnal.fkip.untad.ac.id/index.php/jpmt/article/view/294?articlesBySameAuthorPage $=1$

Mahmudah, I. D., \& Saturni, S. (2017). Kesalahan Siswa dalam Menyelesaikan Soal Program Linier Bentuk Cerita Berbasis Newman Di MAN Salatiga. Seminar Nasional Pendidikan Matematika 2017, 1-8. https://publikasiilmiah.ums.ac.id/handle/11617/8775?show=full

Nurussafa'at, F. A., Sujadi, I., \& Riyadi. (2016). Analisis Kesalahan Siswa dalam Menyelesaikan Soal Cerita pada Materi Volume Prisma dengan Fong' S Shcematic Model For Error Analysis Ditinjau dari Gaya Kognitif Siswa ( Studi Kasus Siswa Kelas VIII Semester II SMP IT Ibnu Abbas Klaten Tahun Ajaran 2013 / 2014 ). Jurnal Elektronik Pembelajaran 
Matematika,

$4(2)$,

$174-187$.

https://jurnal.fkip.uns.ac.id/index.php/s2math/article/view/8404

Rahmawati, D., \& Permata, L. D. (2018). Analisis Kesalahan Siswa dalam Menyelesaikan Soal Cerita Program Linear dengan Prosedur Newman. Jurnal Elektronik Pembelajaran Matematika, 5(2), 173-185. https://jurnal.uns.ac.id/jpm/article/view/26050

Rosanggreni, B. Y., Sugiarti, T., \& Yudianto, E. (2018). Analisis Kesalahan Siswa Dalam Menyelesaikan Soal Cerita Ditinjau Dari Gaya Belajar Kinestetik. Kadikma, 9(1), 61-69. https://doi.org/10.19184/kdma.v9i1.8024

Sugiyono. (2015). Metode Penelitian dan Pengembangan. Yogyakarta: Alfabeta.

Utami, A. D. (2016). Tipe Kesalahan Mahasiswa Dalam Menyelesaikan Soal-Soal Geometri Berdasar Newman's Error Analysis (NEA). Jurnal Ilmiah Pendidikan Matematika, 4(2), 85-92. http://doi.org/10.25273/jipm.v4i2.842 